WANL-TNE-756

April 27, 1964

\title{
SUBMITTED BI:
}

Westinghouse Electric Corporation Astronuclear Laboratory

Pittsburgh 36, Pennsylvania

This report was prepared as an account of work This report was prepared as an account of work The Lited States nor the United States Atomic Energy Common Commission, hor any of therr employees, nor any of their contractors, subcontractors, or their employees, makes any warranty, express or implied, or assumes any

legal liability or responsibility for the accuracy, com

pleteness or usefulness of any information, apparatus,
product or process disclosed, or represents that its use

product or process disclosed, or represen
would not infringe privately owned rights.

INFORMATION CATEGORY

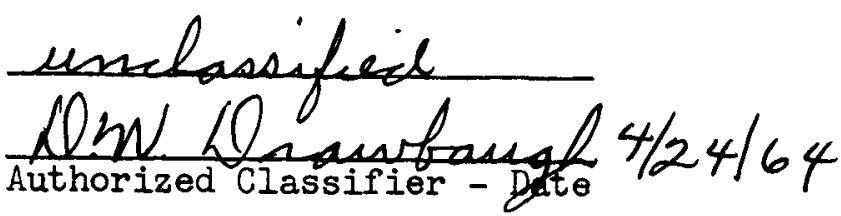

PREPARED BY:

$\frac{\text { C.P. Saalbach }}{\text { C.P. Saalbach }}$

APPROVED BY:

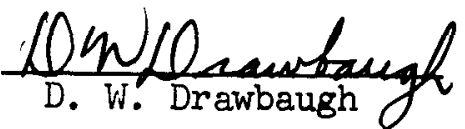

A GENERALIZED

LEAST SQUARES PROGRAM

(Title Unclassified)

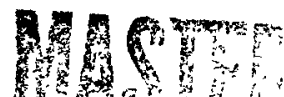




\section{DISCLAIMER}

This report was prepared as an account of work sponsored by an agency of the United States Government. Neither the United States Government nor any agency Thereof, nor any of their employees, makes any warranty, express or implied, or assumes any legal liability or responsibility for the accuracy, completeness, or usefulness of any information, apparatus, product, or process disclosed, or represents that its use would not infringe privately owned rights. Reference herein to any specific commercial product, process, or service by trade name, trademark, manufacturer, or otherwise does not necessarily constitute or imply its endorsement, recommendation, or favoring by the United States Government or any agency thereof. The views and opinions of authors expressed herein do not necessarily state or reflect those of the United States Government or any agency thereof. 


\section{DISCLAIMER}

Portions of this document may be illegible in electronic image products. Images are produced from the best available original document. 


\section{SUMMARY}

This report contains descriptions and directions for use of the following routines:

1. Subroutine ISTSQR - a generalized least squares routine for fitting functions of the type

$$
\mathrm{y}=c_{1} \phi_{1}(\mathrm{x})+c_{2} \phi_{2}(\mathrm{x})+\ldots+c_{\mathbb{N}} \phi_{\mathrm{N}}(\mathrm{x})
$$

to a set of data points. The variable $x$ may represent one or more independent variables.

2. Subroutine POIY - a routine for use with the ISISQR subroutine when the $\phi_{i}$ are polynomial terms in one or more variables.

3. Subroutine PLYTPE - a routine for use with ISTSQR subroutine when the $\phi_{i}$ are polynomial type terms in one or more variables with non-integral exponents.

4. Program FITI - a complete program (which uses LSTSQR and POLI) for fitting polynomial functions to a set of data. Input to this program is described in Appendix $I$.

5. Program FIT2 - a complete program (which uses ISTSQR and PLYTPE) for fitting polynomial type functions with non-integral exponents to a set of data. Input to this program is described in Appendix I.

The program is currently being used by Safeguards Engineering to find a function $\lambda=f(v, \alpha)$ which fits a set of point $s(v, \alpha, \lambda)$ which have been obtained from various programs. The variables $\lambda, v$, and $\alpha$ are:

$$
\mathrm{v}=\text { velocity of a particle in orbit }
$$




$$
\begin{aligned}
\alpha= & \text { angle of reentry into the earth's atmosphere of the orbital } \\
& \text { particle } \\
\lambda= & \text { distance travelled by the particle before touching the } \\
& \text { surface of the earth. }
\end{aligned}
$$

II. METHOD

Consider the generalized least squares problem where given a set of points $\left\{\left(x_{j}, \underset{y_{j}}{E}, j=I, M\right\}\right.$ and a set of functions $\left\{\phi_{i}(x), i=1, N\right\}$ with $N \leqq M$, it is desired to find the $\left\{c_{i}, i=1, N\right\}$ such that the function $y(x)$ where

(I) $y(x)=c_{1} \phi_{1}(x)+c_{2} \phi_{2}(x)+\ldots+c_{N} \phi_{N}(x)$

best fits the set of given points in the least squares sense. This is defined to mean that the function $s\left(c_{1}, c_{2}, \ldots c_{N}\right)$ where

$$
\text { (2) } \begin{aligned}
s\left(c_{1}, c_{2}, \ldots, c_{N}\right)= & \sum_{j=1}^{M} w_{j}\left[y_{j}^{E}-y\left(x_{j}\right)\right]^{2} \\
= & \sum_{j=1}^{M} w_{j}\left[y_{j}^{E}-c_{1} \phi_{1}\left(x_{j}\right)-c_{2} \phi_{2}\left(x_{j}\right)-\right. \\
& \left.\ldots-c_{N} \phi_{N}\left(x_{j}\right)\right]^{2}
\end{aligned}
$$

and $w_{j}$ is a weight associated with each point $j$, must be a minimum with respect to the variables $\left\{c_{i}, i=1, N\right\}$. In the most general problem the independent variable $\mathrm{x}$ may represent a set of independent variables. (Ref. 1)

\section{Examples}

1. Suppose it is desired to fit a polynomial of degree 3 to a set of data points $\left\{\left(x_{j}, y_{j}^{E}\right), j=1, M\right\}$. This is an example of the 
generalized least squares problem with $\phi_{1}(x)=1, \phi_{2}(x)=x$, $\phi_{3}(x)=x^{2}$, and $\phi_{4}(x)=x^{3}$. The problem is to find $c_{1}, c_{2}, c_{3}$, and $c_{4}$ such that

$$
y(x)=c_{1}+c_{2} x+c_{3} x^{2}+c_{4} x^{3}
$$

best fits the given data points in the least squares sense.

2. Suppose it is desired to fit the most general polynomial of degree 2 in two independent variables $r$ and $\theta$ to a set of data $\left\{\left(r_{j}, \theta_{j}, y_{j}^{F}\right), j=1, M\right\}$. This is an example of the generalized least squares problem with $x=(r, \theta)$ and $\phi_{1}(x)=\phi_{1}(r, \theta)=1, \phi_{2}(r, \theta)=r$, $\phi_{3}(r, \theta)=\theta, \quad \phi_{4}(r, \theta)=r^{2}, \quad \phi_{5}(r, \theta)=\theta^{2}$, and $\phi_{6}(r, \theta)=r \theta$. The problem is to find $\left\{c_{i}, i=1,6\right\}$ such that

$$
w(x)=w(r, \theta)=c_{1}+c_{2} r+c_{3} \theta+c_{4} r^{2}+c_{5} \theta^{2}+c_{6} r \theta
$$

best fits the given data points in the least squares sense.

3. Suppose it is desired to fit a finite FOURIER type series of cosine functions to a set of data points $\left\{\left(x_{j}, y_{j}^{E}\right), j=1, M\right\}$. Here $\phi_{i}(x)=\cos (i-1) x$ and it is necessary to find $\left\{c_{i}, i=1, N\right\}$ such that

$$
w(x)=c_{1}+c_{2} \cos x+c_{3} \cos 2 x+\ldots+c_{N} \cos (N-1) x
$$

best fits the given data points in the least squares sense.

Returning to the generalized problem, necessary and sufficient conditions that $s\left(c_{1}, c_{2}, \ldots, c_{N}\right)$ described by (2) have a minimum is that

$$
\text { (3) } \frac{\partial S\left(c_{1}, c_{2}, \ldots, c_{N}\right)}{\partial c_{i}}=0
$$

for all $c_{i}, i=1, N$. Differentiating (2) with respect to $c_{i}$ and setting the result to zero we have 
(4) $\frac{\partial S}{\partial c_{i}}=\sum_{j=1}^{M} 2 w_{j} \phi_{i}\left(x_{j}\right)\left[y_{j}-c_{1} \phi_{1}\left(x_{j}\right)-c_{2} \phi_{2}\left(x_{j}\right)-\ldots\right.$

$$
\left.-c_{N} \phi_{N}\left(x_{j}\right)\right]=0
$$

or after multiplication and transposition

$$
\text { (5) } \begin{gathered}
c_{1} \sum_{j=1}^{M} \phi_{i}\left(x_{j}\right) w_{j} \phi_{1}\left(x_{j}\right)+c_{2} \sum_{j=1}^{M} \phi_{i}\left(x_{j}\right) w_{j} \phi_{2}\left(x_{j}\right)+\ldots \\
+c_{N} \sum_{j=1}^{M} \phi_{i}\left(x_{j}\right) w_{j} \phi_{N}\left(x_{j}\right)=\sum_{j=1}^{M} \mathrm{y}_{j} w_{j} \phi_{i}\left(x_{j}\right)
\end{gathered}
$$

Since there is an equation for each $i$ from $I$ to $N$, we may solve for the $c_{i}$ by solving the following set of simultaneous linear equations:

$$
\begin{gathered}
c_{1} \sum_{j=1}^{M} \phi_{1}\left(x_{j}\right) w_{j} \phi_{1}\left(x_{j}\right)+c_{2} \sum_{j=1}^{M} \phi_{1}\left(x_{j}\right) w_{j} \phi_{2}\left(x_{j}\right)+\ldots \\
\quad+c_{N} \sum_{j=1}^{M} \phi_{1}\left(x_{j}\right) w_{j} \phi_{N}\left(x_{j}\right)=\sum_{j=1}^{M}{ }_{j}^{E} w_{j} \phi_{1}\left(x_{j}\right)
\end{gathered}
$$

(6)

$$
\begin{gathered}
c_{1} \sum_{j=1}^{M} \phi_{2}\left(x_{j}\right) w_{j} \phi_{1}\left(x_{j}\right)+c_{2} \sum_{j=1}^{M} \phi_{2}\left(x_{j}\right) w_{j} \phi_{2}\left(x_{j}\right)+\ldots \\
\quad+c_{N} \sum_{j=1}^{M} \phi_{2}\left(x_{j}\right) w_{j} \phi_{N}\left(x_{j}\right)=\sum_{j=1}^{M}{ }_{j}^{E} w_{j} \phi_{2}\left(x_{j}\right)
\end{gathered}
$$




$$
\begin{gathered}
c_{1} \sum_{j=1}^{M} \phi_{N}\left(x_{j}\right) w_{j} \phi_{1}\left(x_{j}\right)+c_{2} \sum_{j=1}^{M} \phi_{N}\left(x_{j}\right) w_{j} \phi_{2}\left(x_{j}\right)+\ldots \\
+c_{N} \sum_{j=1}^{M} \phi_{N}\left(x_{j}\right) w_{j} \phi_{N}\left(x_{j}\right)=\sum_{j=1}^{M} y_{j}^{E} w_{j} \phi_{N}\left(x_{j}\right)
\end{gathered}
$$

Consider now the following matrices.

$$
\begin{aligned}
& A=\left(\begin{array}{cccc}
\phi_{1}\left(x_{1}\right) & \phi_{2}\left(x_{1}\right) & \ldots & \phi_{N}\left(x_{1}\right) \\
\phi_{1}\left(x_{2}\right) & \phi_{2}\left(x_{2}\right) & \ldots & \phi_{N}\left(x_{2}\right) \\
\phi_{1}\left(x_{3}\right) & \phi_{2}\left(x_{3}\right) & \ldots & \phi_{N}\left(x_{3}\right) \\
\vdots & \vdots & & \vdots \\
\phi_{1}\left(x_{M}\right) & \phi_{2}\left(x_{M}\right) & \ldots & \phi_{N}\left(x_{M}\right)
\end{array}\right) \\
& \mathrm{W}=\left(\begin{array}{ccccc}
w_{1} & 0 & 0 & \ldots & 0 \\
0 & w_{2} & 0 & \ldots & 0 \\
\vdots & \vdots & \vdots & & \vdots \\
0 & 0 & \ldots & 0 & w_{M}
\end{array}\right)
\end{aligned}
$$




$$
\mathrm{C}=\left(\begin{array}{c}
\mathrm{c}_{1} \\
\mathrm{c}_{2} \\
\vdots \\
\mathrm{c}_{\mathrm{N}}
\end{array}\right)
$$

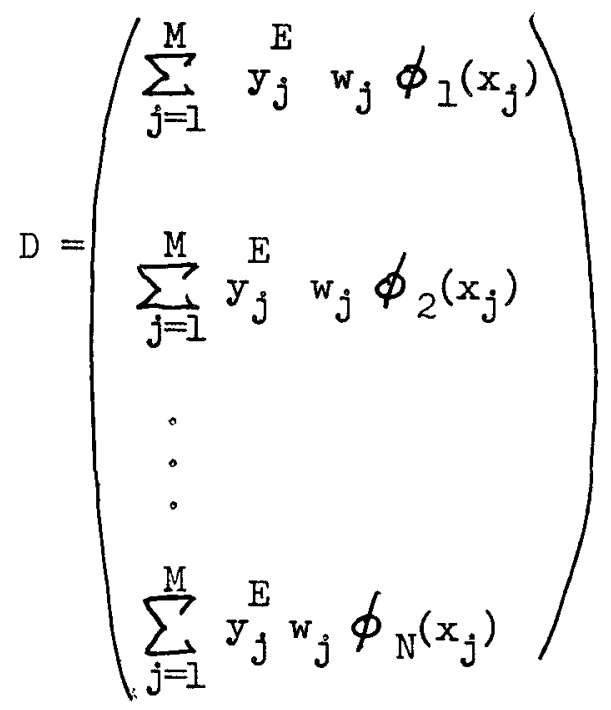

It may be verified by matrix multiplication (Ref.2) that the equations (6) may be represented by the following matrix equation

$$
\text { (7) }\left(A^{T} W A\right) C=D
$$

where $A^{T}$ is the transpose of $A$ (i.e. the matrix $A$ with the rows and columns interchanged). The element $d_{m, n}$ in the mth row and nth column of the matrix $A^{T} W A$ is precisely the coefficient of $c_{n}$ in row $m$ of equations (6), i.e., $\mathrm{A}^{\mathrm{T}} \mathrm{WA}$ is the matrix of the coefficients of the $c_{i}$ in equations (6).

The least squares subroutine requires as input the matrices $A$ and $W$ and the values $\left\{y_{j}^{E}, j=1, M\right\}$. It calculates the matrix $A^{T} W A$ and the vector $D$, and solves equation (7) for the vector $c$ using the ISIMEQ subroutine for solving simultaneous linear equations.

\section{THE PROGRAM}

The purpose of writing the LSTSQR subroutine was to supply the user with a routine which is completely independent of the functions $\phi_{i}(x)$ in equation ( 1 ). The burden of choosing these functions and the evaluation 
of the matrix A is placed upon the user. However, since polynomial type functions are so widely used for fitting curves, two other routines, POLY and PLYTPE, are supplied for the evaluation of the matrix A when the $\phi_{i}(x)$ are polynomial type terms. The subroutine POLY uses fixed point exponentiation and can be used when the functions $\phi_{i}$ are products of any number of variables with integral (positive or negative) exponents. Examples of such $\phi_{i}$ are $x^{3}, x^{2} y^{-3}, x y^{-5} z^{4}$, etc. Subroutine PLYTPE is used when the $\phi_{i}$ are products of any number of independent variables, and any of the variables have non-integral (positive or negative) exponents. Examples of such functions are $x^{\frac{1}{2}}, x^{2} y^{.56}, x^{.27} y^{-1.7} z^{3}$, etc. The subroutine PLYTPE will, of course, solve any problem which can be solved with the POLY routine. The POLY routine is supplied for those cases where there may be concern for the computer time used in floating point exponentiation. Output of the LSTSQR subroutine consists of $y_{j}$ and $y_{j}^{E}$ for the given data points and the percentage error $\left(\mathrm{y}_{j}^{E}-\mathrm{y}_{j}\right) / \mathrm{y}_{j}^{E}$. Also calculated is the standard error SIGMA $=\frac{1}{M} \sum_{j=1}^{M}\left(y_{j}^{E}-y_{j}\right)^{2}$. The coefficients $c_{i}$ are also available for use.

Considerable effort was expended to make LSTSQR a general, fast, and small subroutine. In addition, the routine is very conservative of storage in that only $\mathrm{N}^{*}(\mathrm{~N}+1)$ temporary storage locations are required. 
IV. USAGE

A. Subroutine LSTSQR

1. Calling sequence with $A$ as a one dimensional variable

CALI ISTSQR (A, Y, W, NCOF, NPTS, IADIM, NMBRA)

where

ivCOF $=$ number of functions $\phi_{i}(x)$ in equation $(1)$. (Same as $N$ )

NPTS $=$ number of given data points. (Same as M)

IADIM must be zero. This the control which tells LSTSQR that $\mathrm{A}$ is a one dimensional array.

NMBRA is the dimension of $A$. This must be at least as large as NCOF $*(N P T S+N C O F+1)$.

$A=a$ one dimensional array where the matrix $A$ is stored. The following rules apply:

a. $\phi_{1}\left(x_{1}\right), \phi_{1}\left(x_{2}\right), \ldots, \phi_{1}\left(x_{M}\right)$ must be stored in $A$ (l) through A(NPTS) followed by $\phi_{2}\left(x_{1}\right), \phi_{2}\left(x_{2}\right), \ldots$ $\phi_{2}\left(x_{M}\right)$ in $A(N P T S+1)$ through $A(2 * N P T S)$, etc.

b. The coefficients $c_{i}$ are stored in A(NCOF*NPTS+1) through $A(N C O F * N P T S+N C O F)$ upon return from the subroutine.

c. LSTSQR destroys $\mathrm{A}(\mathrm{NCOF} * \mathrm{NPTS}+1)$ through $\mathrm{A}(\mathrm{NCOF} *$ $(\mathrm{NPTS}+\mathrm{NCOF}+1)$ ).

$Y$ is a one dimensional array containing $\mathrm{y}_{1}, \mathrm{y}_{2}, \ldots, \mathrm{J}_{\mathrm{M}}$ in $Y(1)$ through $Y$ (NPTS).

$W$ is a one dimensional array containing the weights $w_{1}, w_{2}, \ldots, w_{M}$ in $w(I)$ through $w(N P T S)$.

2. Calling sequence with $A$ as a two dimensional variable

CALI ISTSQR ( A, Y, W, NCOF, NPTS, IADIM, NMBRA) where 


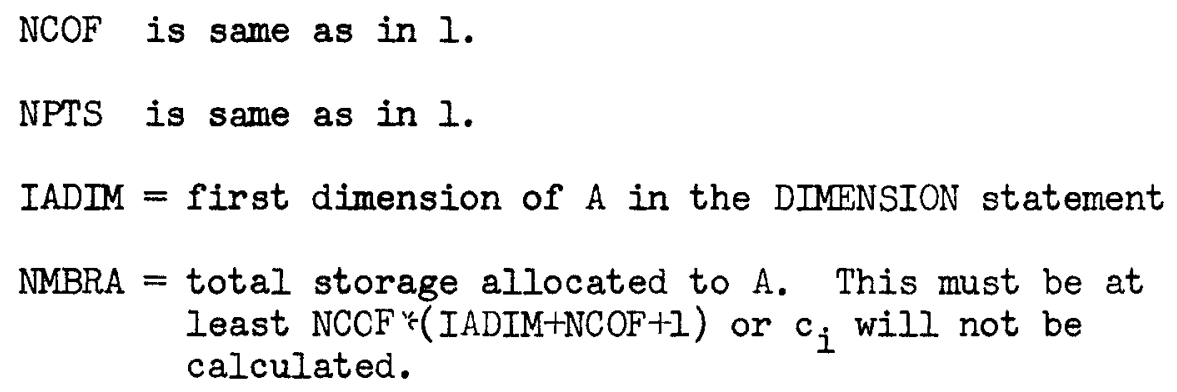

$A$ is a two dimensional variable where the matrix $A$ is stored. $\phi_{j}\left(x_{i}\right)$ is stored in $A(I, J)$. The $c_{i}$ are returned in $(A(I, N C O F+1), I=1, N C O F)$

$Y$ is the same as in 1.

$W$ is the same as in 1.

B. Subroutine POLY

\section{General Description}

The purpose of the POLY subroutine is to construct the A matrix needed in the ISTSQR routine when the functions $\phi_{i}(x)$ are polynomial type terms with positive or negative integral exponents. Examples of such $\phi_{i}$ are $x^{2}, x y^{-3}, x^{2} y z^{-5}$, etc. The routine requires the values of the independent variables where the $y_{j}^{E}$ are known, and the exponents of the independent variables in the individual polynomial type terms.

\section{Calling Sequence}

CALL POLY (NVAR, NPTS, NCOF, IPWR, A, X)

NVAR $=$ total number of independent variables in the $\phi_{i}$ NPTS $=$ number of points where $\mathrm{y}^{\mathrm{E}}$ is known

$\mathrm{NCOF}=$ number of polynomial type terms in the fitted function. The constant term, if present, is counted as one of these terms. 
IPWR is a singly dimensioned variable containing the exponents for each of the polynomial type terms. They are arranged in the following manner:

IPWR(I) to IPWR(NVAR) - exponents for Ist polynomial term $\operatorname{IPWR}($ NVAR+1) to IPWR(2*NVAR) " " 2nd

$\cdot$

$\cdot$

IPWR (NVAR $*(N C O F-1)+1)$ to IPWR (NVAR*NCOF) - exponents for the last polynomial term

IPWR may contain positive, negative or zero values.

The zero value designates the absence of the corresponding independent variable in that term. The constant term is described by all zero exponents.

A is a singly dimensioned output argument which will contain the matrix A which is needed in the LSTSQR routine.

$X$ is a singly dimensioned variable containing values of the independent variables for NPTS points. They are arranged in the following manner:

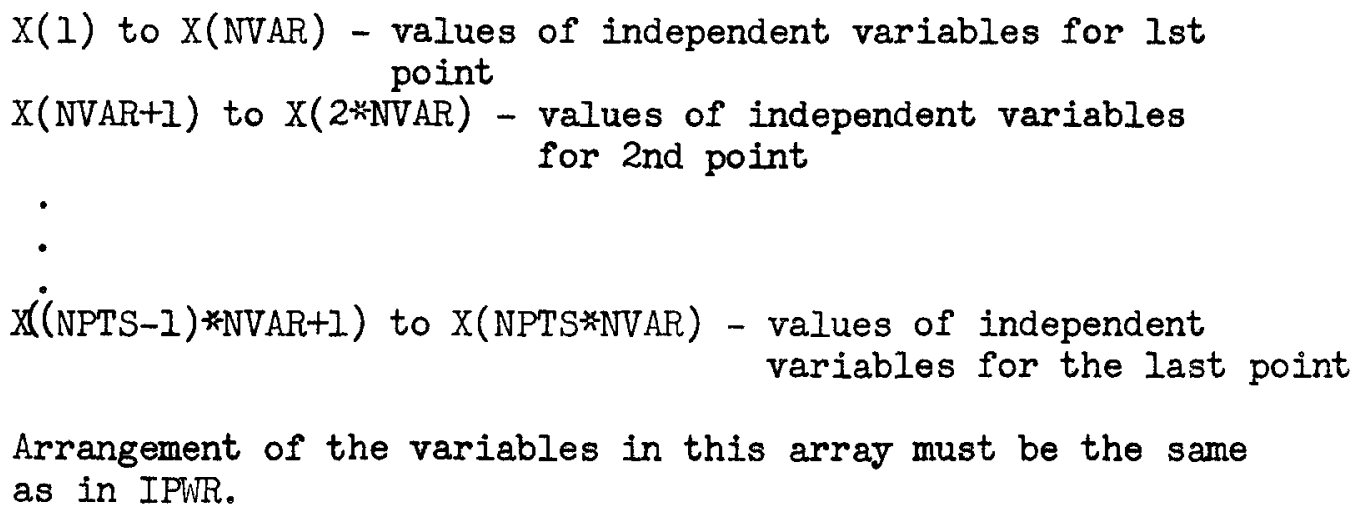

3. Example

Construct the matrix A for the polynomial

$y=c_{1}+c_{2} r^{2}+c_{3} \theta^{2}+c_{4} r \theta$

when the following 12 points are given: 

C. Subroutine PLYTPE

1. General Description

The purpose of the PLYTPE routine is exactly that of the POLY routine except that the exponents may be non-integral.

2. Calling Sequence

CALI PLYTPE (NVAR, NPTS, NCOF, XPWR, A, X)

The description of the arguments is exactly the same as the

POLY routine except for XPWR. The XPWR variable description is the same as for IPWR, except that XPWR contains floating point exponents.

V. ACKNOWLEDGNENT

The author wishes to express his thanks to T. Manning of IBM for his help with this program. 
Nomenclature

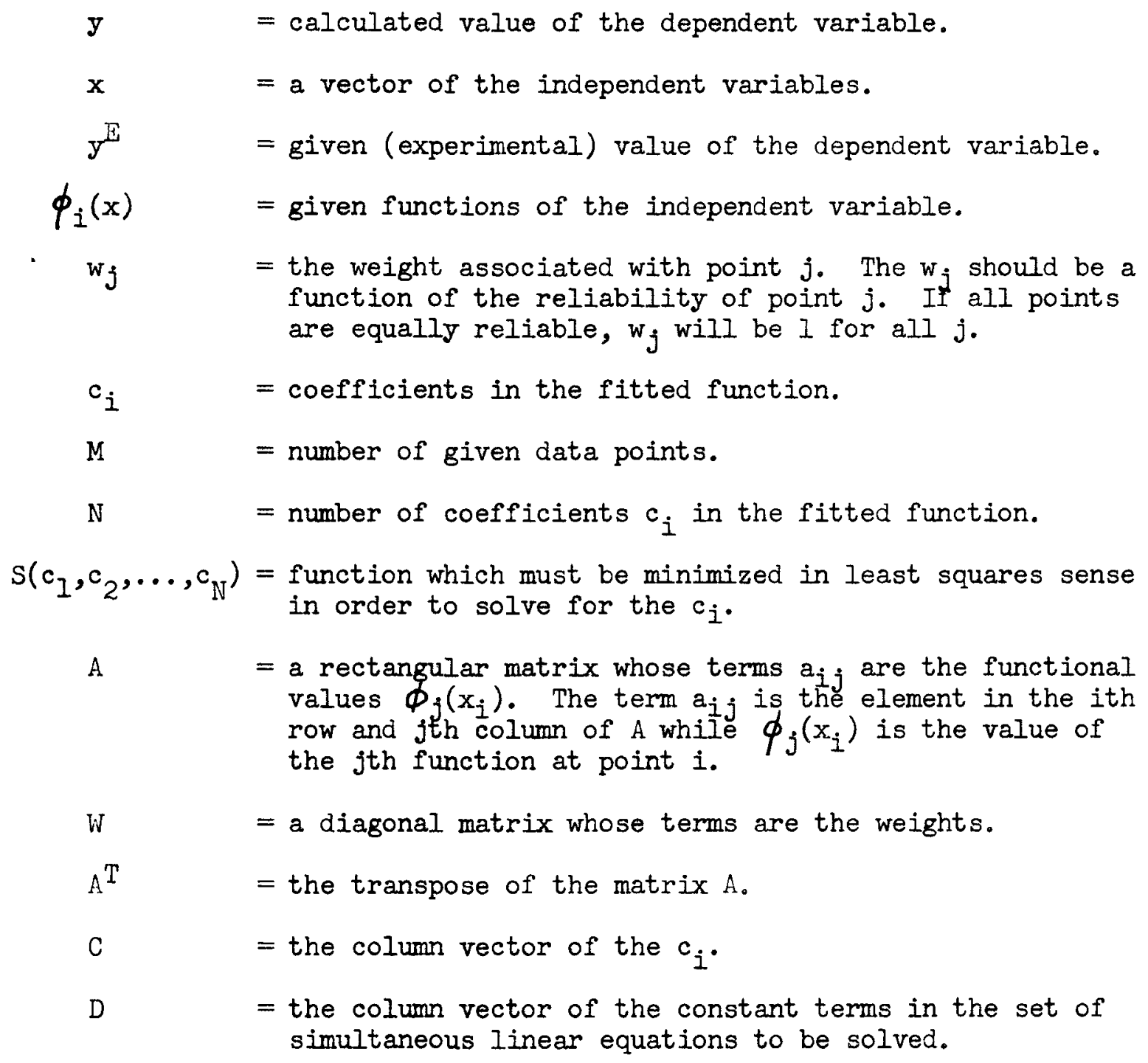




\section{References}

1. F. B. Hildebrand, Introduction to Numerical Analysis, McGraw-Hill Company, $258-262,(1956)$.

2. G. Birkhoff and S. MacLane, A Survey of Modern Algebra, Macmillan Company, 209-213, (1954). 


\section{APPENDIX I}

\section{^. FITI Program}

\section{Purpose}

The FITI program fits polynomials in any number of independent variables to a given set of data points. The exponents in the polynomial may be positive or negative integers or zero. It should be cautioned that when negative exponents are used, the domain of the independent variables should not include a pole of the fitted function.

\section{The Program}

The FITl program consists of a main program and the subroutines LSTSQR and POLY. The ISTMEQ routine, which solves a set of simultaneous linear equations, is also required. This is a regular library routine on the Westinghouse Astronuclear System Tape.

\section{Input}

a. Card 1 FORMAT (13A6, A2)

This is a card of title information.

b. Card 2 FORMAT (3I5)

Contains NVAR, NCOF, and NPTS where NVAR = number of independnet variables

$\mathrm{NCOF}=$ number of coefficients in the polynomial including the constant term

NPTS $=$ number of given data points

c. Next Cards FORMAT ( $\left.\mathbb{6}_{\mathrm{E}}^{\mathrm{E}} 2.5\right)$

Punch the values of the independent variables followed by the value $y^{E}$ followed by the weight for that point. Use as many cards as are necessary for each point but begin each new point on a new card. Cards must be supplied for NPTS points. 
If the weight field is left blank (this field may not be omitted), the weight for this point will be set equal to 1.

d. Next cards FORMAT (14I5)

Punch the values of the exponents of the independent variables in each of the polynomial terms. Begin each new term on a new card and supply cards for NCOF terms. A zero exponent is used to indicate the absence of the corresponding variable in that term, and the constant term is described by all zeros.

e. Example

Fit the polynomial

$$
\mathrm{z}=\mathrm{c}_{1}+\mathrm{c}_{2} \mathrm{r}^{2}+\mathrm{c}_{3} \theta^{2}+\mathrm{c}_{4} \mathrm{r} \theta
$$

in the two independent variables $r$ and $\theta$ to the following 12 data points:

\begin{tabular}{llll}
$r$ & & $\theta$ & $\mathrm{y}^{\mathrm{E}}$ \\
\cline { 4 - 4 } 0 & & 1 & 2 \\
0 & 2 & 5 \\
0 & 3 & 10 \\
0 & 4 & 17 \\
1 & 1 & 4 \\
1 & 2 & 8 \\
1 & 3 & 14 \\
1 & 4 & 22 \\
2 & 1 & 8 \\
2 & 2 & 13 \\
2 & 3 & 20 \\
2 & 4 & 29
\end{tabular}

The following page gives the input for this problem. The computer solution is given in Appendix II. 


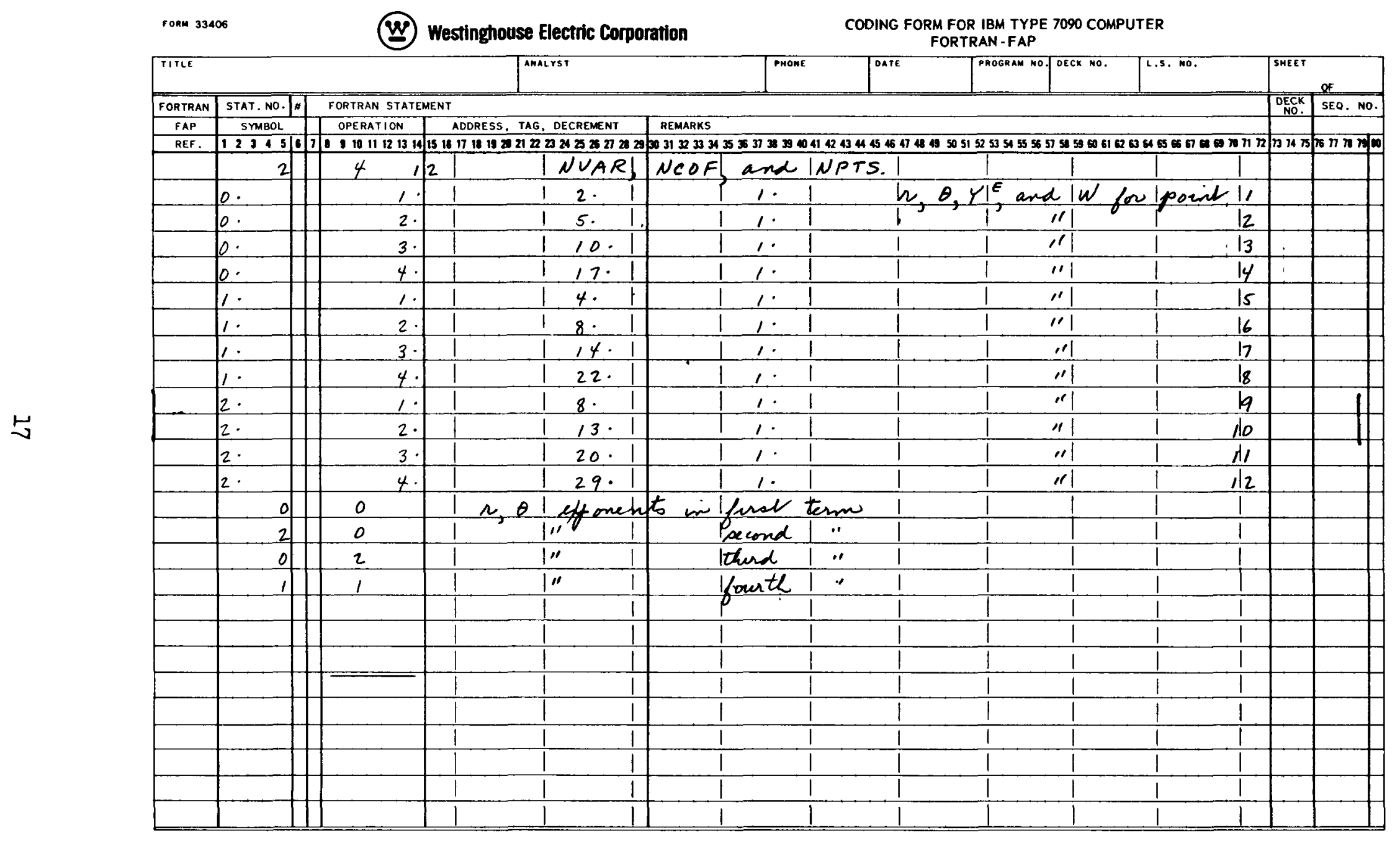


B. FIT2 Program

1. Purpose

The FIT2 program fits polynomial type functions in any number of independent variables to a given set of data points. The exponents may be any real numbers. It should be cautioned that when negative exponents are used, the domain of the independent variables should not include a pole of the fitted function.

2. The Program

The FIT2 program consists of a main program and the subroutines LSTSQR and PLYTPE. The ISIMEQ routine, which solves a set of simultaneous linear equations, is also required. This is a regular library routine on the Westinghouse Astronuclear System Tape.

3. Input

Input is identical with the FITI program except for the cards containing the exponents. The description of these cards is the same except for the format, which for floating point exponents is now FORMAT (6E12.5). 
APPENDIX II

PROGRAM AND SAMPIE PROBLEMS 
C MAIN PROGRAM FOR FITI PRDGRAM. MAY RF USED FOR FITTING PCLYNCMIAL

C FUNCTIONS IN ANY NUMBER OF VARIABLES: A GIVEN SET OF POINTS.

COMMON $A, Y, W, X, I P W R$

DIMENSION A(150CO), Y(1000),W(1CC0), X(8000), IPWR:50C)

DIMENSION TITLE $(1+)$

C

C READ AND PRINT TITLE.

5 READ INPUT TAPE $5,103,1$ TI:LE:I: $1=1,14$ )

WRITE OUTPLT TAPE $6,104,(11$ ILE (I), $1=1,14)$

$c$

C READ NO. OF VARIABLES, NU. OF COEFFICIENTS, AND NC, OF POINTS.

READ INPUT TAPE $5,100, N V A R, N C O F, N P T S$

$\mathrm{N} 1=1$

N2 $=$ NVAR

$c$

C READ DATA POINTS AND WEIGHTS.

c

DO $1 I=1$, NPTS

READ INPUT TAPE $5,101,(X(J), J=N 1, N 2), Y(1), h(1)$

$N 1=N 1+N V A R$

$1 N 2=N 2+N V A R$

C

C READ POWERS.

$N 1=1$

N2 $=$ NVAR

DO $21=1, N C O F$

READ INPUT TAPE $5,1 C 2,(I P W R(J), J=i N 1, N 2)$

$N 1=N 1+N V A R$

$2 N 2=N 2+N V A R$

\section{c \\ c}

SET ALL ZERO WEIGHTS TC 1.0

DO $31=1$, NPTS

IF (W(I) $3,4,3$

$4 W(I)=1.0$

3 CONTINUE

C

C poly calculates a matrix. 
104 FORMAT (IHI 13A6.A?)

END 
SUBROUTINE POLY(NVAR, NPTS, NCOF, IPWR, $A, X)$

C SUbroutine poly Calculates the matrix a neEded by the lstsqr routine.

C THE ARGUMENTS ARE

C NVAR = NUMBER CF INDEPENDENT VARIABLES IN POLYNOMINL.

C NPTS = NUMBER OF GIVEN DATA PCINTS.

C NCOF = NUMBER OF TERMS IN THE POLYNCMIAL。

C

C

C

IPWR IS THE ARRAY WHERE THE EXPONENTS ARE STORED。

$X$ IS THE ARRAY WHERE VAI.UES OF THE INDEPENDENT VARIABLES ARE STDRED。

A IS THE ARRAY WHERE POLY STORES THE MATRIX A.

DIMENSION IPWR (2),A(2), X(2)

NVR1 $=$ NVAR

NPT $1=$ NPTS

NCF1 $=$ NCOF

$I 1=1$

$N 1=1$

DO 1 I $2=1, N C F 1$

$\mathrm{N} 2=1$

N3 $=$ NVR 1

DO 2 I $3=1, N P T 1$

$\mathrm{I} 4=\mathrm{N} 1$

$A(I)=1.0$

DO $3 \quad$ I $5=\mathrm{N} 2, \mathrm{~N} 3$

IF(IPWR(I!)) $4,3,4$

$4 A(I 1)=A(I 1) *(X(I 5) * I P W R(14))$

3 I $4=I 4+1$

$N 2=N 2+N V R 1$

$N 3=N 3+N V R I$

$2 I I=I I+1$

$1 N \mathbf{I}=N \mathbf{N}+N V R \mathbf{I}$

RETURN

END 
SUBROUTINE LSTSQR (A,Y,W,NCCF \&NPTS, IADIM, NMBRA)

$c$
$C$
$C$
$C$
$C$
$C$
$C$
$C$
$C$
$C$
$C$
$C$
$C$
$C$

SUBROUTINE LSTSQR CALCULATES THL MATRICES (AT W A) AND D ANU SCLVES

THE MATRIX EQUATION IAT W $* A I \times C=D$ FCR C USING THF ISIMEQ

SUBROUTINE. THE ARGUMENTS OF LSTSQR ARE

A IS A ONE OR TWO DIMENSIONAL ARRAY WHERE THE MATRIX A

IS STORED.

$Y$ IS A ONE DIMENSIONAL ARRAY WHERE YE IS STORED.

$W$ IS AN ARRAY WHERE THE WEIGHTS ARE STORED.

NCOF $=$ NUMBER OF UNKNOWN COEFFICIENTS IN THE FITTED FUNCTION.

NPTS = NUMBER OF GIVEN DATA POINTS. ALSO NUMBER OF Y AND $W$.

IADIM = O IF A IS ONE DIMENSIONAL.

IADIM = FIRST DIMENSION OF A IF A IS TWD DIMENSIONAL.

NMBRA = TOTAL NUMBER OF STORAGE SPACES ALLOCATED TO A.

DIMENSION $A(2), Y(2), W(2)$

NCF1 $=$ NCOF

NPT $1=$ NPTS

$I A I=I A D I M$

$I 1 D=0$

IF (IAI) $12,13,12$

C

C

INITIALIZE IID AND NI IF A IS TWO DIMENSIONAL.

12 I $1 D=I A 1-N P T 1$

$N 1=N C F 1 * I A 1$

GO TO 14

$c$

C

CALCULATE NI if a is one Dimensional.

$13 \mathrm{~N} 1=N C F 1 * N P T 1$

$14 \mathrm{~N} 2=\mathrm{N} 1+1$

$N 3=N I+N C F I$

$N 4=N 1+N C F 1 * N C F 1+1$

$N 5=N 4+N C F 1-1$

C

C

TEST IF A IS TOO SMALL.

IF (NMBRA-N5) $1,2,2$

1 WRITE OUTPUT TAPE 6,100

CALL EXIT

calculate the symmetric matrix at*W*a. The upper half only 
C IS CALCULATED. AT*W*A IS STORED BY COLUMNS IN CONSECUTIVE

C LOCATIONS BEGINNING IN AINCCF NPTS+I) IF A IS ONE DIMENSIONAL,

C AND BEGINNING IN A(1,NCOF+1) IF A IS TWO DIMENSIONAL.

$\mathrm{C}$

2 DO $3 \quad I=N 2, N 5$

$3 A(I)=0$.

$I 1=1$

DO $4 \quad 12=1$, NCF 1

DO 5 I $3=1$. NPT 1

$Z=A(I 1) * W(13)$

$14=11$

DO $6 \quad I 5=N 2, N 3$

$A(15)=A([5)+A(I 4) * Z$

$614=I 4+N P T 1+I 1 D$

$5 \quad 11=11+1$

$I 1=11+110$

$16=\mathrm{N} 2$

C

C SET LOWER HALF OF A EQUAL TO UPPER HALF.

DO $7 \quad 17=\mathrm{N} 2, \mathrm{~N} 3$

$A(16)=A(I 7)$

$716=16+N C F 1$

$N 2=N 2+N C F 1+1$

$4 N 3=N 3+N C F 1$

c

C Calculate the matrix D.

C

$I 1=1$

DO $1112=N 4, N 5$

DO 8 I $3=1, N P T 1$

$A(I 2)=A([2)+W(I 3) * A(I 1) * Y(13)$

$8 I 1=I 1+1$

$11 I 1=I 1+110$

$N 6=N 1+1$

C

C SOLVE FOR C.

C

CALL ISIMEQ(A (NG), NCFI, NCF 1, I)

WRITE DUTPUT TAPE $6,101,(A(I), I=N 4, N 5)$

$I 1=N I+1$

DO $15 \mathrm{I}=\mathrm{N} 4, \mathrm{~N} 5$

$A(I)=A(I)$ 
$1511=11+1$

WRITE OUTPUT TAPE 6,102

SIGMA $=0$.

C CALCULATE Y FROM FITTED FUNCTIOM' CALCULATE PERCENTAGE DIFFEREN'

$C$ OF $Y$ AND YE. ALSO CALCULATE STANUARD ERROR.

C

DO $9 \mathrm{~J}=1$, NPI 1

$Z=0$.

$I 1=J$

DO $10 \quad 12=\mathrm{N} 4, \mathrm{~N} 5$

$Z=Z+A(11) * A(12)$

$10 \quad 11=I 1+N P T 1+I 10$

$D E L=Y(J)-Z$

SIGMA $=$ SIGMA+DEL $* D E L$

$D E L=D E L / Y(J)$

9 WRITE DUTPUT TAPE $6,103, Y(J), 2, D E L$

$F N=N P T I$

SIGMA = SQRTF(SIGMA/FN)

WRITE DUTPUT TAPE 6,104, SIGMA

RETURN

100 FORMAT (52H1 DIMENSION OF A MUST BE AT LEAST NCCF*(NPTS+NCOF+1)

101 FORMAT(22HO THE COEFFICIENTS ARE/1H /(6E16.6))

102 FORMATI1H1 $8 X, 1 H Y 15 X, 2 H Y C$ 12X,5HDELTA/1H)

103 FORMAT (3E 16.6$)$

104 FORMAT(12HO SIGMA IS E14.6)

END 
FITTING $(\mathrm{Cl}+\mathrm{C} 2 * \mathrm{R} * 2 * 2+\mathrm{C} 3 * \mathrm{TH} * 2+C 4 * R * T H) \mathrm{TO}(1+\mathrm{T} * 2 * 2+\mathrm{TH} * 2+R * T H)$

THE COEFFICIENTS ARE

$0.100000 E 01 \quad 1.000000 E$ CO $1.000000 E$ OO $0.100000 E 01$ 


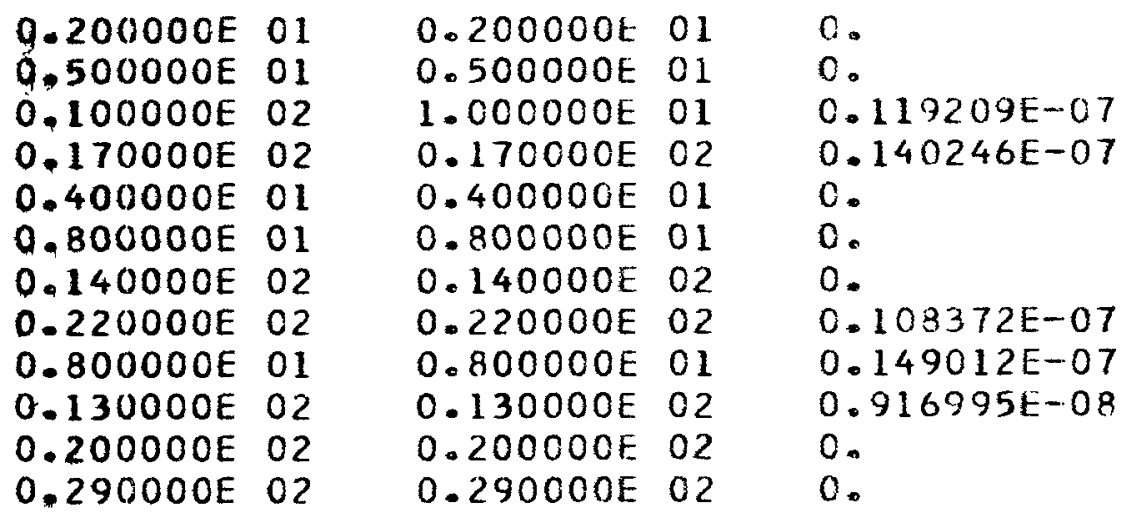

SIGMA IS $0.114134 E-06$ 
C MAIN PROGRAM FOR FIT 2 PROGRAM - MAY BE USED FOR FITTING POLYNOMIAL

C TYPE FUNCTIONS WITH INTEGRAL OR NON-INTEGRAL POWERS TO A GIVEN SET

C OF DATA POINTS. FUNCTIONS MAY HAVE ANY NUMBER OF VARIABLES.

C

COMMON $A, Y, W, X, X P W R$

DIMENSION A(15000), Y(1000),W(1000),X(8000),XPWR(500)

DIMENSION TITLE (14)

$\mathrm{C}$

C READ AND PRINT TITLE.

C

5 READ INPUT TAPE $5,103,\{$ TITLEII $), I=1,14\}$

WRITE OUTPUT TAPE $6,104,(T$ ITLE(I), I $=1,14)$

$c$

C

READ NO. OF VARIABLES, NO. OF COEFFICIENTS, AND NO. DF POINTS

READ INPUT TAPE $5,1 C 0$, NVAR,NCOF,NPTS

$N 1=1$

$N 2=N V A R$

c

C READ DATA POINTS AND WEIGHTS.

DO $1 \quad I=1$, NPTS

READ INPUT TAPE $5,101,(X(\mathrm{~J}), \mathrm{J}=\mathrm{N} 1, N 2), Y(I), W(I)$

$N 1=N 1+N V A R$

$1 N 2=N 2+N V A R$

C READ POWERS.

C

$N 1=1$

$N 2=N V A R$

DO $21=1$, NCOF

READ INPUT TAPE $5,101,(X P W R(J), J=N 1, N 2)$

$N I=N I+N V A R$

$2 N 2=N 2+N Y A R$

C

C SET ALL ZERO WEIGHTS IO 1.0

DO $3 I=1$, NPTS

IF(W(I)) $3,4,3$

$4 W(I)=1.0$

C

3 CONTINUE 


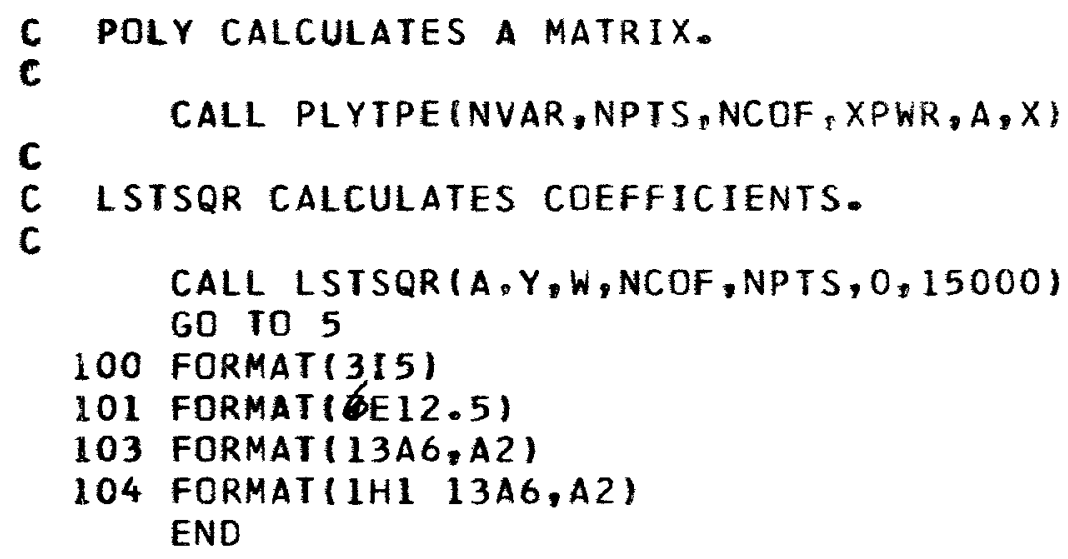

103 FORMAT (13A6.A2)

104 FORMAT (1H1 13A6,A2)

END 
SUBROUTINE PLYTPE (NVAR, NPTS, NCOF, XPWR, $A, X)$

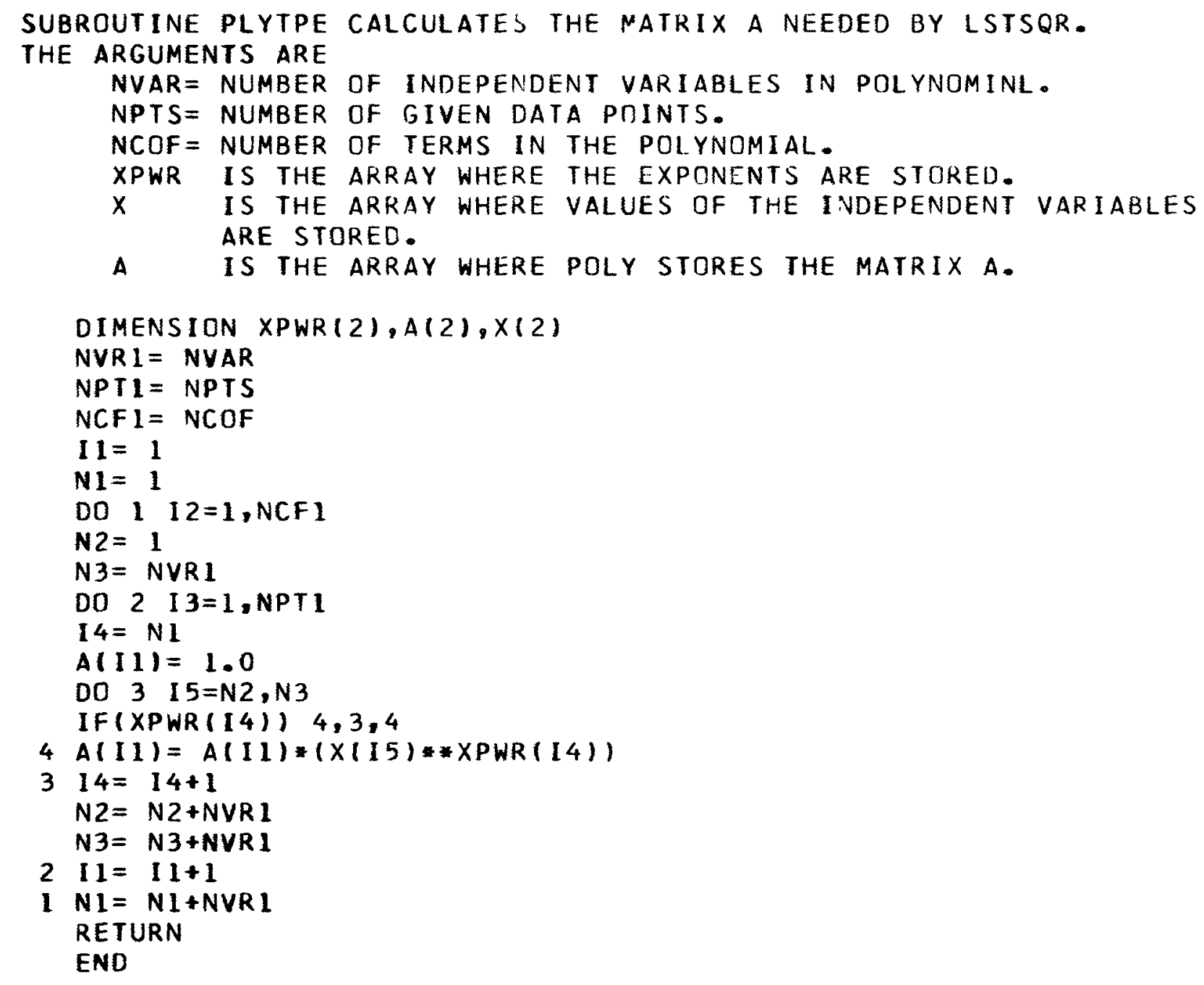

